\title{
The Causal Relationship of the Social Support and Maladaptive Perfectionism with the Academic Burnout Mediated by the Self-Efficacy among Undergraduate Students of Shahid Chamran University
}

\author{
Azizi Abarghuei, M. \\ Ph.D Student of Educational Psychology, Faculty of Educational Sciences and Psychology, Allameh Tabataba'l University, Tehran
}

Falsafinejad, M. R.*

Ph.D of Psychometrics, Associate Professor in Psychometric and Educational Psychology Group, Faculty of Educational Sciences and Psychology, Allameh Tabataba'I University, Tehran ${ }^{*}$ Corresponding Author: E- mail: falsafinejad@yahoo.co.uk

\section{Ebrahimi Ghavam, S.}

Ph.D of Educational Psychology, Associate Professor in Psychometric and Educational Psychology Group, Faculty of Educational Sciences and Psychology, Allameh Tabataba'I University, Tehran

Dortaj, F.

Ph.D of Psychology, Professor in Psychometric and Educational Psychology Group, Faculty of Educational Sciences and Psychology, Allameh Tabataba'I University, Tehran

\section{Doi:10.5901/mjss.2016.v7n4s1p11}

\begin{abstract}
The aim of this research was to investigate the causal relationship between the social support and maladaptive perfectionism on the one hand and the academic burnout mediated by the self-efficacy in the undergraduate students of Shahid Chamran University. The statistical population of research was included all students of the semester 5 upward of Shahid Chamran University of Ahvaz. The reason for selecting the students of the semester 5 upward was that the academic burnout is created over time. For sampling at first the cluster method was used and then the relative stratified sampling method and finally 520 samples in total were analyzed. To measure the research variables the Maslach burnout inventory - student survey, the social support of Malecki, Damary and Elliott, perfectionism of Stoeber and the general Self-efficacy of Scherer were applied and for analyzing the data the path analysis method was used. The results showed that the presented model has a good fitness. Explanations related to the hypotheses and the proposed pattern were discussed, the restrictions were mentioned and practical suggestions also were provided.
\end{abstract}

Keywords: academic burnout, social support, maladaptive perfectionism, self-efficacy

\section{Introduction}

Higher education as the highest educational level of society has a considerable importance, because it plays an essential role in the development of society in technological, scientific, cultural, economic, social and political dimensions. This course plays an important role in improving the quality of different sectors of society Sabaghyan (2004); quoted by Abtahi, \& Torabian, (2010). Increasing the international understanding, improvement of the entire educational system, creating an attitude and readiness in individuals for acquiring the continuing education, promoting research at the highest level, developing the critical reasoning skills, encouraging social equality, protecting the freedom of faculty members etc. are the missions of higher education. Mentioned system as a source of changes and leading them in direction of the elevation of society in line with the complete fulfilment of the mission, objectives and assigned duties must be of necessary efficacy and effectiveness; so maintaining, improving and enhancing the quality of this system are the factors that should be the priority of its measures and programs (Abtahi, \& Torabian,M, 2010).

Every year many students enter enthusiastically and with a hope for the future the higher education institutions and 
it is expected to continue this enthusiasm and motivation so that it helps in the best possible way to promote the country. The higher education system should provide the conditions the students can with enthusiasm and interest, confidence and efficacy sensation be able to learn continuously and in the future continue their lives with enthusiasm, motivation and hope. One of the major obstacles that cause to reduce the motivation and performance of students of higher education institutions and build up the negative consequences such as reducing growth and development of students, depression, decreasing mental health etc. and has been considered most recently by researchers, is academic burnout. Burnout is a state of mental and emotional fatigue that is a result of chronic stress syndrome like the role overload, pressure and time constraints and lack of the necessary resources to carry out the assigned duties. (Demerouti et al., 2001; Lee \& Ashforth , 1996; Lacovides et al., 2003; Maslach et al., 2001; Toppinen Tanner et al., 2005). This phenomenon and its negative consequences that was observed first in the professional and job environment and became famous by the name of burnout, was followed by many researches. Job burnout is defined as one of important indicators of psychological wellbeing with the three dimensions of exhaustion, apathy (cynicism) and inefficacy. (Maslach, Schaufeli, \& Leiter, 2001). In the job area the burnout can be led to the less commitment and productivity, absenteeism and leaving job (Cordes \& Dougherty, 1993; Maslach, Pines., 1977; quoted by Yang, 2004). But this phenomenon is not limited to work environments and these symptoms were also observed in other environments. Researches about the burnout in situations like vendors (Sand \& Miyazaki, 2000), teachers (Greenglass et al., 2001), nurses (Zellars et al., 2000), consultants (Ross et al., 1989) and psychologists (Sandeval, 1993) were performed (Maslach \& Jackson, 1984). However, the burnout variable has been expanded to the educational situations and contexts and entitled as the academic burnout (Salmela-Aro et al., 2009). There are evidences that show the existence of the burnout phenomenon in students (Meier \& Schmeck, 2006; quoted by Yang \& Farn, 2005). Educational burnout among college students (college) refers to the feeling of fatigue because of the demands and requirements of education (fatigue), having a cynical sense to individual's homework (apathy), and feeling of lack of competence as a student (low efficacy) (Schaufeli et al, 2002; Zhang et al., 2007). It can be said that educational situations are considered as the learners' workplace, although learners in educational situations do not work as an employee or have not there a certain job, but from a psychological perspective their educational activities could be considered as a "work" (Salmla-Aro, 2009). They are present in the class and do a set of assignments for success in exams and earn passing scores. This issue has allocated recently several studies in universities. (Balogun et al., 1996; Chang et al., 2000; Fimian et al., 1986; Gold et al., 1989; Martinez et al., 2002; McCarthy et al., 1990; Yang, 2004; Naami, 2009; Azizi Abarghuei , 2010).

In some universities a quarter of the students are suffering from burnout. In some universities also burnout is the main reason for dropping out of school of some students (Santrock, 2003; translated by Firouzbakht, 2006). Individuals who have the educational burnout experience usually symptoms such as lack of enthusiasm towards teaching materials, inability to maintain a continuous presence in the classroom, not participating in classroom activities, feeling a meaninglessness in instructional activities and a feeling of inability in the learning materials (Naami, 2009). Depression is another phenomenon associated with burnout (Weissman \& Klerman, 1979; quoted by Yang \& Farn, 2005). Eslami (2011) found a significant negative relationship between academic burnout and psycho-physical health. Burnout can be led to mental stress in the form of anxiety, depression, frustration, hostility or fear (Young, 2004). Researches in this area in Iran have a short history, but there is a great interest to this area. Some researches in Iran (e.g. Saviz, 2012; also N.k Dadvar, 2014) show that the academic burnout (or some of its components) in the lower levels of education (undergraduate compared to graduate, graduate compared to $\mathrm{PhD}$ ) is observed further. Conducted researches have examined often separately the relationships between personality characteristics, sources of support, training facilities on the one hand and educational burnout on the other; considering that the academic burnout is a multi-causal variable, a causal model to explain the relationships between these variables is necessary. Through identifying the role of each of the factors influencing academic burnout, it can be hoped to prevent it with a proper planning. Undoubtedly, prevention or treatment of burnout will benefit the students, university professors and also for the higher education system and society in general. Students who continue their activities willingly and with the motivation and without skeptical and with confidence guarantee their mental health and look to the future with hopeful vision and also act and work enthusiastically in the society.

Researches on the educational psychology have shown that the several internal and external factors are of effect on the academic burnout. Social support is a variable that has an outward aspect in relation to learners and can have an impact on burnout and academic performance. The social support is the ability and quality of communication with others that provide resources in necessary occasions. Social support is a mutual help that causes to create a positive selfconception, self-acceptance, feeling of love, and self-respect and in all of these cases gives to the individual the selfactualization and growth opportunity (Pourseyed, 2011). Mir and Shemack (1985, quoted by Young, 2004) have noted that the students who are suffering from academic burnout often are lacking in focus and are tired of the routine process 
of class. Russell $(1987$, quoted by Young, 2004) has explained that the individuals who are lacking in the social support is affected easily by stress. In the present research the social support will be investigated as a predicting variable for academic burnout.

In order to prevent and intervene it has been conducted many studies and researches for identifying the antecedents and variables predicting the burnout that include both of environmental aspects and individual aspects ( Langelaan, Bakker, Van Doornen, \& Schaufeli, 2006; Maslach et al., 2001; Schaufeli \& Bakker, 2004; quoted by Zhang et al., 2007). One of these intra-individual variables is the perfectionism. Hamachek (1978; quoted by Porseyedi., 2011) divides the perfectionism in two normal and abnormal dimensions. In the normal perfectionism the individuals enjoy from the hard and painstaking work, they are motivated by the aim of successfulness and also with emphasizing the criteria of the high level of performance can accept the personal and social limitations. In contrast the maladaptive perfectionists are motivated by the fear of failure and due to unrealistic expectations do not never satisfy with the own performance. Some recent researches have shown that the negative and maladaptive perfectionism predict the academic burnout (Zhang et al., 2007). In general the adaptive perfectionism is associated with psychological well-being and academic and suitable job performance, but the maladaptive perfectionism is associated with depression, low self-esteem and symptoms of mental illness (Kelly, 2010; quoted by Pourseyedi, 2011). In the present research the maladaptive perfectionism will be investigated as a variable predicting the academic burnout.

The researches that have been conducted in relation to the teachers' job burnout have used the perceived teacher self-efficacy as one of the predicting variables of the job burnout. Also Salanova and PeirÃ (2002) have worked about self-efficacy and burnout among the employees of information technology. In the academic realm also it has been investigated the role of self-efficacy in the academic burnout (see Azizi Abarghuei, 2010). Self- efficacy "is said one's belief to be able to do something successfully" (Woolfolk, 2004; quoted by Saif, 2009). Self- efficacy is very effective on the individual's behavior. For example the student of low self-efficacy bay be not even prepared for an exam, because he thinks that the more he works hard, the less is his success (Santrook, 2004; quoted by Saif, 2009). In contrast, a person of a high self-efficacy is more hopeful and more successful in doing works (Saif, 2009). In the past decades, researchers have used the theory of self-efficacy to explain the phenomenon of burnout (Schaufeli et al., 1993; quoted by Yang \& Farn, 2005). In describing the relationship between burnout and physiological states, some previous researchers have confirmed the relationship between self-efficacy and burnout (Cherniss, 1992, 1993; Hallsten, 1993; \& Hobfoll \& Freedy, 1993). They have shown that individuals without a sense of mastery and skill (such as self-efficacy) are easily suffering from the burnout and usually lose the ability to adapt. Based on done researches it can be said that the academic burnout in educational situations is determined with features such as the fatigue caused by requirements related to study, development of a pessimistic sense and attitude and being non-sensitive to instructional materials and also a weak sense of personal development in the educational affaires (Salmela-Aro \& Naatanen, 2005). Based on self-efficacy theory and previous researches that were mentioned to some of them, the self-efficacy in present research is investigated as an important internal and individual variable associated with academic burnout.

The relationship between the maladaptive perfectionism and academic burnout in some researches has been investigated and confirmed, including the Pourseyed (2011), Shah Bakhsh (2011) and Zhang et al. (2006); but the mechanism of the effect of maladaptive perfectionism on burnout in present research is investigated through the mediation of the self-efficiency variable. The researchers such as Vanlentin JC, Dubois (2004; quoted by Toutounchi et al., 2011) found a strong relationship between academic self-conception of students and their progress. Besharat et al. (2011) have shown that self-efficiency in the relationship between perfectionism and competitive anxiety acts as a mediator. Fouladvand et al. (2009) in a research have come to the conclusion that the relationship between social support and mental-physical health is mediated through variable of the academic self-efficiency. Also in research of Danielson (2009) the academic competence and general self-efficiency have played the role of mediator in the relationship between classmate's support and life satisfaction. In the present research the self-efficiency is investigated as the mediating variable in the relationship between social support and maladaptive perfectionism with academic burnout.

In fact, the aim of this research is to present a conceptual pattern of the impact of personality factors (such as maladaptive perfectionism) and supportive resources in the education environment (classmate's support) on the educational important consequences such as academic burnout. In this research the self-efficiency variable has been considered as a mediating variable. The relationships between the research variables in this pattern have been developed based on existing research literature.

As it was expressed, there are many research evidences that confirm separately the relationships between the antecedent variables (maladaptive perfectionism, social support) and its consequences (academic burnout) and also the mediator variable (self-efficiency) and its mediating role in the relationships between the antecedent variables and 
consequences. As it was shown, there is an enough theoretical justification for these relationships; but in the obtained research history that considers the relationships of this pattern simultaneously and as a general pattern was not observed. Especially there are many models related to the burnout variable in the job environment, but in the educational space it is felt a necessity for explaining the relationship between the variables through modeling. Figure 1 shows the proposed model in the present research.

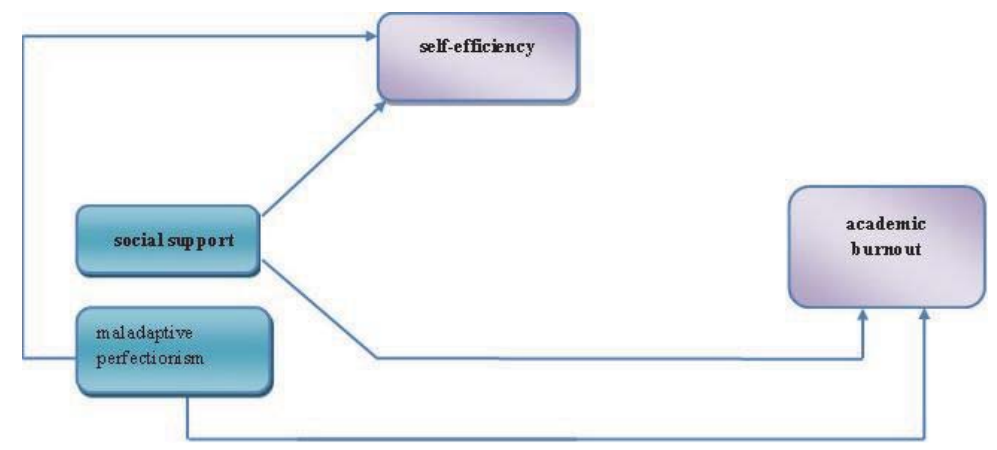

Figure 1: The proposed pattern of the present research, the relationship between antecedent variables, mediator and consequence

\section{The Research Hypotheses}

- Maladaptive perfectionism has a direct effect on academic burnout.

- The classmate's support has a direct effect on academic burnout.

- Maladaptive perfectionism has an indirect effect (through self-efficacy) on academic burnout.

- The classmate's support has an indirect effect (through self- efficacy) on academic burnout.

\section{Research Method}

Research design: the present research is of the non-experimental and correlation type. In the researches aimed to test a model of the relationships between variables, the path analysis or model of structural equations is used. The present research design is the causal modeling through the path analysis. The path model is one of the models that can be benefited in explaining and predicting the different phenomena.

\subsection{The statistical population and sampling methods}

\subsubsection{The statistical population}

The statistical population of research was included all undergraduate students of semester 5 upward of Shahid Chamran University in the academic year 2012-13. The reason for choosing the students semester 5 upward is that the academic burnout is created over time and the influencing factors in the creation of burnout must affect for a time the individual.

\subsubsection{The sampling method}

For sampling first four faculties from the total of faculties of Shahid Chamran University (the number of faculties of Shahid Chamran University of Ahvaz are eleven) were selected randomly (these faculties include the literature, economy, education sciences, and natural sciences); then by using the relative stratified sampling method were selected 550 individuals of the female and male (considering the potential falling) in the selected faculties were selected by approximate ratio of 70 to $30 \%$ respectively (according to the percentage of girls and boys in the study population). In order to determine the sample size based on the Krejsie and Morgan's table the number of sample according to the number of individuals of population must be a number between 360 to 380 individuals. But since the present research has investigated numerous variables and some experts believe that in such studies the sample size should be greater 
than the studies with few variables and also taking into consideration the possible falling 550 individuals were selected. One of the guides for the selection of sample size in the multivariate studies (studies in which there are numerous independent and dependent variables) is as follows:

50 = very weak, 100 = weak, $200=$ acceptable, $300=$ good, $500=$ very good and $1000=$ excellent (Comery 1971; quoted by Biyabanghard, 2008).

\subsection{Measuring tool}

Maslach's questionnaire of academic burnout of version of students: This questionnaire measures three areas of academic burnout, namely the educational fatigue, educational apathy (pessimism) and educational inefficiency. The scale of academic burnout of students is Maslach's modified general scale of burnout (MBI-GS) that has been created by Schaufeli et al. (1996) (Schaufeli et al., 2002). The mentioned questionnaire has 15 matter. Of course the scale has had originally sixteen matter that one of its matters has been removed by the suggestion of Schutte et al. (2000). The scoring method of the questionnaire is by the seven-point Likert scale ranging from never (0) to always (6). The educational fatigue has 5 matters (course materials are boring), the educational apathy 4 matters (I feel I do not interest to course materials) and educational inefficiency 6 matters (I feel I can't succeed in the problems of the course). Reliability of the questionnaire has been calculated by its creators respectively $.70, .82, .75$ for three areas of academic burnout. The researchers have calculated the validity of the questionnaire with the confirmatory factor analysis method; they have reported the matching fitness indicators, incremental fitness indicator and indicator of root mean square of error of approximation as favorable. Naami (2009) has calculated the reliability of this questionnaire for the educational fatigue .79 , for the educational apathy .82 and for the educational inefficiency .75 . He has achieved the validity coefficients of this questionnaire by correlating it with the student stress questionnaire (Pouladi Rayshahri, 1995) that have been calculated respectively as to equal $.38, .42, .45$ that at the level of $P<0.001$ is significant. In the research of Azizi Abarghuei (2009) the calculated Cronbach's alpha for the whole questionnaire was obtained .85 and for areas of emotional exhaustion, pessimism and instructional inefficiency respectively .77, .82, .66. Research of Rostami, Abedi and Schaufeli (2011) on 238 female students of Isfahan University that were selected by simple random sampling was performed. Data were presented by using the descriptive statistics and drawing graphs and they had a normal distribution. The obtained raw scores were transformed into scores of $T$ and $Z$ and percentile ranks and the norm tables were calculated separately for academic burnout subscales. In order to determine reliability of this tool two methods of the internal similarity and retest were used. The Cronbach's alpha coefficient for the subscales of the emotional exhaustion, and doubt and self-efficacy were obtained respectively $0.88,0.90,0.84$ that indicates the appropriate reliability of this tool. The alpha coefficient in the retest method for the subscales of the emotional exhaustion was 0.89 , and for doubt 0.84 and self-efficacy 0.67 . The factor validity of the test was calculated also by the method of factor analysis and Varimax rotation. To calculate the convergent and divergent validity the questionnaire of students' depression and researcher-made scale of the interest in the field of education were used respectively. The alpha coefficient for the divergent validity for the subscales of emotional exhaustion, doubt and self-efficacy was obtained respectively $-0.21,-0.53,-0.32$. Hashimi Sheikh Shabani, Bazrafkan, and Azizi (2013) investigated the psychometric properties of Maslach's academic burnout questionnaire (MBISS) in female students who have a master's degree. In order to complete the questionnaire of the academic burnout by the stratified random sampling method 124 graduate female students participated. The analysis of principal components of the three factors (pessimism, emotional exhaustion and inefficiency) showed that $53.70 \%$ in total explained the scale variance. Also the results showed that based on the analysis of the structure of confirmatory factor both two three-factor model based on the findings of analysis of principal components and based on the findings of the principal creator had the more fitness with data rather than the one-factor model. The results obtained for the internal similarity of total scale and its factors indicated the acceptable reliability of scale. The correlation between each one of scale items and the total score was changeable from 0.33 to 0.75 and it was significant. The correlation of the academic burnout scale and its dimensions with the quality of learning experiences and self-efficacy was significant. With regard to the validity and reliability of the academic burnout scale it can be used this scale to measure the academic burnout.

In the present research the coefficient of internal similarity of questionnaire through calculation of Cronbach's Alpha has been obtained 0.88 and through the Guttman coefficient (dividing-in-half) 0.88 .

The scale of social support for children and adults: This scale (CASSS) that was created by the Malecki, Demaray, and Elliott (2000) contains 60 questions which measure 5 support sub-components. These sub-components consist in: parents, teachers, classmates, close friends, staff and the individuals at the school. The authors have calculated the questionnaire alpha indicator in high school students as equal to 0.97 . Also they have reported the retest reliability that was carried out between 8 to 10 weeks later, in the students of lower ranks between 0.75 up 0.78 . To obtain the validity 
the creators have calculated the correlation between this questionnaire and the Social Skills questionnaire (ssrs) of Gresham \& Elliott (1990, quoted by the creators of the questionnaire) as equal to 0.64 that is significant in the level P $<001$. To calculate the validity of questionnaire it was taken a correlation between this questionnaire and the social support questionnaire of Phillips that the amount of 0.48 was obtained; that is at the level of $P<005$ significant. In the present research also the coefficient of internal similarity of questionnaire through calculation of Cronbach's Alpha has been obtained 0.94 and through the Guttman coefficient (dividing-in-half) 0.89 . In this research the sub-scale of classmate's support of this questionnaire was used.

Perfectionism questionnaire of Stoeber et al.: Negative perfectionism in this research has been evaluated through the perfectionism questionnaire designed by Stoeber et al. (2007; quoted by Pourseyed, 2011). This questionnaire (including positive and negative perfectionism) contains ten questions. Alizadeh (2009) has calculated the reliability coefficients of this questionnaire through Cronbach's alpha for its two parts respectively 0.80 and 0.84 . He has calculated at the same time the validity coefficient of this questionnaire, the correlation of matters with perfectionism scale of Ahvaz (Najarian, Atariyan and Zargar, 2001). The results showed that trying to achieve perfection -0.63 and the negative reaction to the failure at achieving perfection 0.68 have correlated with the Ahvaz Perfectionism scale that is significant in the level of $P<001$. In the present research the coefficient of internal similarity of questionnaire through calculation of Cronbach's Alpha has been obtained 0.84 and through the Guttman coefficient (dividing-in-half) 0.75 .

The Sherer's general self-efficacy questionnaire: This questionnaire was created in 1982 by Sherer and his colleagues and it has 23 items from which 17 items are related to general self-efficacy and 6 another items the experiences of self-efficacy in the social situations (Najafi \& Fouladchang, 2007). In this research the scale of 17 items was used. The self-efficacy questionnaire measures the individual's beliefs in relation to his ability to overcome the different situations. This questionnaire has been set based on the five ranks scale of Likert so that the response of completely opponent receives the score 1 and the response of completely agreeable the score 5 . Sherer et al. (1982) obtained 0.86 as the Cronbach's alpha of this questionnaire and to assess the validity of the component scale of the selfefficacy used its correlation with Rotter's internal-external control scale, subscale of IE of Goyinla and Biti in 1969, scale of grade of social capability of Marlowe and Croaw in 1964, scale of self-alienation of Baroon in 1953 and scale of individual merit of Rosenberg in 1965 (Barati, 1997; quoted by Najafi \& Fouladchang, 2007). According to the carried out investigations it is obtained a medium negative correlation between the scores of self-efficacy and internal-external control scale, a medium positive correlation between the scale of social ability grade and self-efficacy and a medium positive correlation between the self-alienation and competence on the one hand and self-efficacy on the other (Najafi \& Fouladchang, 2007). Also their studies showed that there is a positive correlation between the scores of this questionnaire and success in jobs and education. Keramati (2001) obtained its Cronbach alpha in Iranian samples 0.86. Barati (1997; quoted by Najafi \& Fouladchang, 2007) to obtain the validity of the test component has reported its correlation with the self-esteem scale as equal to 0.61 . He has obtained the reliability of self-efficacy test in the high school students level 3 by using the Spearman-Brown method with equal length of 0.76 and with unequal length of 0.76 and with Gutman's dividing-inti-half method he has earned 0.76 . He obtained in order to ensure the reliability the Cronbach's alpha in the sample as equal to 0.80 . Najafi and Fouladchang (2007) reported also Cronbach's alpha of this questionnaire as 0.80 . In the present research the coefficient of internal similarity of questionnaire through calculation of Cronbach's Alpha has been obtained 0.88 and through the Guttman coefficient (dividing-in-half) 0.85 .

\section{Descriptive Findings}

Before doing the main analyses, it was performed several initial analyses to gain preliminary insights in relation to the data. In this research the relationships between the variables of the proposed pattern were in total evaluated. The descriptive findings about the average, standard deviation, minimum and maximum of the scores of subjects on the research variables (Table 1) and the correlation matrix of the variables of pattern have been shown in Table 2.

Table 1: Descriptive findings related to the research variables for all subjects

\begin{tabular}{lcccc}
\hline Statistics variables & max & Min & s.d. & average \\
\hline Maladaptive perfectionism & 30 & 5 & $5 / 049$ & $16 / 708$ \\
\hline Classmate's support & 72 & 2 & $11 / 993$ & $42 / 803$ \\
\hline Self-efficacy & 84 & 26 & $10 / 001$ & $60 / 605$ \\
\hline Academic burnout & 85 & 00 & $14 / 879$ & $39 / 0169$ \\
\hline $\mathrm{N}=520$ & & & &
\end{tabular}


As contents of table 1 show, the descriptive indicators including the average and standard deviation have been provided for the total sample in the variables of perfectionism, the classmate's support as the predicting variables and self-efficacy as a mediating variables and the variable of academic burnout as the dependent variable.

Table 2: The correlation coefficient matrix of the pattern variables

\begin{tabular}{|c|l|c|c|c|}
\hline & 4 & 3 & 2 \\
\hline 1 & Perfectionism & $0 / 35^{* *}$ & $-0 / 32^{* *}$ & $-0 / 11^{* *}$ \\
\hline 2 & Classmate's support & $-0 / 24^{* *}$ & $0 / 20^{* *}$ & - \\
\hline 3 & Self-efficacy & $-0 / 51^{* *}$ & - & - \\
\hline 4 & Burnout & - & - & - \\
\hline
\end{tabular}

As contents of Table 2 show, the presumed scheme of relationships between the variables is largely correspondent with the expected path and the relationships are significant. These analyses of the correlation have provided an insight into the two-variate relations between the variables of research. In order to test simultaneously the scheme of the assumed relations in the present research the path analysis method has been applied.

\subsection{Fitness of the research model}

In the present research in order to evaluate the fitness of the model the fitness of existing indicators were used in table 3.

Table 3: The final and proposed pattern fitness with the data on the basis of indicators of fitness

\begin{tabular}{|c|c|c|c|c|c|c|c|c|c|c|c|}
\hline $\begin{array}{c}\text { indicators of fitness } \\
\text { pattern }\end{array}$ & RMSEA & NFI & CFI & TLI & IFI & AGFI & GFI & P & $\frac{\chi^{2}}{d f}$ & $d f$ & $\chi^{2}$ \\
\hline proposed pattern & $0 / 055$ & $0 / 988$ & $0 / 993$ & $0 / 957$ & $0 / 993$ & $0 / 975$ & 1998 & $/ 116$ & $2 / 464$ & 1 & $2 / 464$ \\
\hline
\end{tabular}

As it can be seen in table 3, the very good fitness indicators are obtained which show a good fitness to the data with this pattern.

\subsection{The findings related to indirect relations}

In this section we investigate the mediation relationships by method of Baron and Kenny (1986). The basic conditions of this method are the significance of the simple correlations between existing variables in the relationships under test. According to Table 2 the simple correlation coefficients are significant among all variables. These relationships fulfil the desirable basic prerequisites of Baron and Kenny (1986). The next step is the use of the method of the hierarchical regression in order to investigate the mediating relationships between the variables.

Table 4: Results of hierarchical regression coefficients in two stages in investigating the role of the mediating variable

\begin{tabular}{|c|c|c|c|c|c|c|c|}
\hline \multirow{2}{*}{ Model } & & \multirow{2}{*}{$\mathrm{R}$} & \multirow{2}{*}{ Sig. } & \multirow{2}{*}{$\mathrm{t}$} & Standard coefficients & \multicolumn{2}{|c|}{ Non-standard coefficients } \\
\hline & & & & & Beta & St. error & $B$ \\
\hline \multirow{2}{*}{1} & Fixed & \multirow{2}{*}{$0 / 354$} & $0 / 001$ & $17 / 259$ & - & $2 / 114$ & $36 / 481$ \\
\hline & perfectionism & & $0 / 001$ & $8 / 624$ & $0 / 354$ & $0 / 121$ & $1 / 044$ \\
\hline \multirow{3}{*}{2} & fixed & \multirow{3}{*}{$0 / 552$} & $0 / 001$ & $18 / 557$ & - & $4 / 508$ & $83 / 666$ \\
\hline & perfectionism & & $0 / 001$ & $5 / 498$ & $0 / 213$ & $0 / 114$ & $0 / 627$ \\
\hline & Self-efficacy & & $0 / 001$ & $-11 / 524$ & $-0 / 446$ & $0 / 058$ & $-0 / 663$ \\
\hline
\end{tabular}

Table 4 shows that the perfectionism and self-efficacy are used both simultaneously as the predicting variables of the academic burnout in the regression equation. As it is show in the contents of above table, when the variable of selfefficacy as the second predicting variable is added to variable of perfectionism, the amount of the regression coefficient of the first predicting variable (perfectionism) decreases worthlessly and its coefficient remains still significant. This state 
confirms the incomplete mediating effect of the self-efficacy in this case.

Table 5. Results of hierarchical regression coefficients in two stages in investigating the role of mediating variable

\begin{tabular}{|c|c|c|c|c|c|c|c|}
\hline \multirow{2}{*}{ Model } & & \multirow{2}{*}{$\mathrm{R}$} & \multirow{2}{*}{ Sig. } & \multirow{2}{*}{$\mathrm{T}$} & Standard coefficients & \multicolumn{2}{|c|}{ Non-standard coefficients } \\
\hline & & & & & Beta & St. error & $B$ \\
\hline \multirow{2}{*}{1} & Fixed & \multirow{2}{*}{0,237} & 0,001 & $28 / 241$ & - & $2 / 355$ & $66 / 504$ \\
\hline & classmate's support & & 0,001 & $-5 / 544$ & $-0 / 237$ & 0,053 & $-0 / 294$ \\
\hline \multirow{3}{*}{2} & Fixed & \multirow{3}{*}{0,531} & 0,001 & $28 / 742$ & - & 3,658 & $105 / 127$ \\
\hline & classmate's support & & 0,001 & $-3 / 668$ & $-0 / 139$ & 0,047 & $-0 / 173$ \\
\hline & self-efficacy & & 0,001 & $-12 / 766$ & $-0 / 485$ & 0,057 & $-0 / 722$ \\
\hline
\end{tabular}

Table 5 shows that the classmate's support and self-efficacy are used both simultaneously as the predicting variables of academic burnout in the regression equation. As it is show in the contents of above table, when the variable of selfefficacy as the second predicting variable is added to classmate's support, the amount of the regression coefficient of the first predicting variable (classmate's support) decreases, but its coefficient remains still significant. This state confirms the incomplete mediating effect of the self-efficacy in this case.

\section{Discussion and Conclusion}

The present research was conducted to investigate the causal relationship between social support and maladaptive perfectionism on the one hand and academic burnout on the other mediated by self-efficacy in undergraduate students of Shahid Chamran University. As it was shown, the proposed model has had a good fitness and hypotheses related to direct and indirect relationships were confirmed.

According to the findings of the present research some researches examine the simple relationship between the perfectionism and academic burnout and confirm it, for example Shahbaksh (2010), Pourseyed (2011), Saviz (2012). In explaining the result of this hypothesis it can be said that the maladaptive perfectionism includes selection of high and unrealistic criteria in various fields such as the academic affairs, too much worry about one's mistakes, the difference between the performance and individual criteria, obsessive doubts about personal actions and motivation for avoiding negative consequences rather than the motivation to achieve positive consequences (Enz \& Cokx, 2002).

The next hypothesis is the indirect relationship between maladaptive perfectionism and the academic burnout through the mediating variable of self-efficacy. The relationship between the maladaptive perfectionism and the academic burnout in some researchs has been investigated and confirmed, including Poursaeid (2011), Shah Bakhsh (2011) and Zhang et al. (2006); but the mechanism of the effect of the maladaptive perfectionism on burnout in the present research was clarified through the mediation of self-efficacy variable. Researchers such as Valentin JC and Dubois (2004; quoted by Toutounchi et al., 2011) found a strong relationship between academic self-conception of students and their progress. Besharat et al (2011) also have shown that the self-efficacy in the relationship between perfectionism and competitive anxiety acts as a mediator. One of the behavioral and cognitive style of perfectionists is the comprehensive anxiety of incompleteness. At the university the academic performance feedbacks are many and varied, for example the weekly or monthly quizzes, midterm exams and end of semester, an annual competition to receive scholarships and so forth. So an absolute self-image that students have kept in mind is easily changed or with the mistakes and carelessness, or with real problems in specific subjects (Zhang et al., 2006). In general, life is full of the potentially threatening events such as exams and perception of personal performance (self-efficacy) in determining how these events bring with themselves much stress and anxiety for the individual plays an important role. "Threat" rather than being a fixed feature of events depends always on the relationship that the individual has established with the task. If someone knows that his capabilities can't cope with the necessities of an event, this awareness brings the thoughts of failure, emotional arousal, feeling of distress and anxiety (Bandura, 1983; Bandura, Rees, \& Adams, 1982; Bandura et al., 1985; Lazarus, a1991; quoted by Rio, John Marshall, 2001; translated by Sayed Mohammad, 1383). Hamachek (1978) observed that the of the perfectionists have very high anxiety about their actual tasks. According to them, these tasks must be done completely and absolutely well. The efforts of these individuals, even at their best, never is good enough. These individuals set for themselves the difficult standards and goals that are beyond their abilities. According to Bandura some individuals try always to do things beyond their capabilities and therefore are defeated and despair of, and probably eventually give up everything (Olson \& Hergenhan, 2009, translated by Saif, 2012). In fact, the incompatible perfectionists with severe self- 
criticism, determining the criteria beyond the level of ability, delay in getting things done and such wrong practices increase their anxiety levels, and reduce their self-efficacy and thereby it is paved the way to the incidence of academic burnout in these individuals.

The other hypothesis was the effect of social support on academic burnout. According to research findings, some researches examine the simple relationship between social support and academic burnout and confirm it, for example Pourseyed (2011), Saviz (2012).

Regarding the role of social support in relation to stress and burnout, different explanations such as the role of a shield, mediator, and preventive have been discussed. Social support is a concept that helps an individual to deal with environmental stress. Researchers have proved that individuals with more social relationships have good health and life longer, better and more productive as they are deprived of these relationships. People who are under environmental stress by providing social support to each other are able to control the pressure and partly to reduce its severity. For Cohen and Syme (1985) even the perception that people in stressful situations support and assist the individual can have positive effects on psychological states. Social support can reduce the severity of stressful events and therefore is of important effects on the experience of events. Social support can with a sense of self-esteem and sense of control enable individual to effectively deal with stressful events and prevent the consequences of negative events of stress. Having a sense of control and high self-esteem causes to reduce the importance of a source of stress and increases the amount of dealing with stress (House, 1981; quoted by Ganster \& Victor, 1988). As we know, burnout is considered as a consequence of a chronic stress.

The indirect effect of social support on academic burnout was approved also through self-efficacy.

Fouladvand et al. (2009) in a research came to this conclusion that the relationship between the social support and mental-physical health is mediated through academic self-efficacy variable. Also in the research of Danielson (2009) the academic competence and general self-efficacy in the relationship between classmate's support and life satisfaction played a mediating role. In this study, the mechanism of the effect of social support on academic burnout by mediation of the self-efficacy variable became clearer. Positive interaction between students may develop the need to competence and autonomy through a shared focus on learning activities. Sharing the methods of problem-solving, giving and receiving positive responses about tasks, providing positive attitudes about homework and encouraging dialogue and collaboration of students, the social support of classmates can offer an effective support in the field of learning (Danielson, 2009). Social support can influence the amount of the educational self-efficacy in many ways like the reward and punishment while engaging in the activities. Feedback received from others and the assurance received from others about amount of ability to conduct educational activities can enhance the educational self-efficacy of individual and influence the individual's belief as to the ability for doing educational activities, control and domination over them (Fouladvand et al.). This self-efficacy may underlie the reduction of burnout in individual. Major et al. (Quoted by Fouladchang, 2003) believe that self-efficacy beliefs influence the amount of effort and time a person spends in dealing with obstacles and unpleasant experiences. Amount of effort and perseverance that each individual spend in doing a task is under the influence of amount of his self-efficacy beliefs. This means that if an individual feels that he can afford to do a task will try to do it, otherwise he will give up it with minimal effort. Self-efficacy determines the amount of individuals' effort, their perseverance and tenacity in dealing with obstacles and resistance to difficult situations (Shank, 1981; quoted by Khateri, 2005). The more the sense of self-efficacy in individual, the more insistent efforts he will have to do the work as well as it will be reduced amount of stress and anxiety (Pajariz \& Miller, 1994; quoted by Khateri, 2005). So one's efficiency will have a profound impact on the final level of doing the work (Pajares \& Shank, 2001; quoted by Khateri, 2005). Also, the higher the amount of self-efficacy beliefs, individual's negative reaction to the failure will be less. These individuals do not think of failure as a sign of the inability, but as a lack of effort and therefore they do not disappoint (Fouladchang, 2003). So it seems that classmate's support with increasing the level of self-efficacy may have a role in reducing burnout.

One of the limitations of the present study is the use of questionnaire as a tool and being a cross-sectional research that makes it difficult to inference the causality.

Due to the characteristic of maladaptive perfectionism in the creation of academic burnout, it is suggested to do interventions in this field. First, it is suggested to be held the useful instructional workshops about knowing the nature of perfectionism and distinction between the adaptive perfectionism and maladaptive one and the necessary instructions have been provided about the ways to cope with maladaptive perfectionism and transforming it into adaptive perfectionism. Second, due to the role of stringent expectations in creating and sustaining maladaptive perfectionism, it is suggested that our teachers adjust their expectations by students (without bring them down and reducing the severity side).

Given the role of social support by classmates in reducing academic burnout, to dear students we suggest that 
they are not indifferent to their classmates and in doing homework help their friends and if possible do the collaborative activities with together. Another issue goes back to professors' supportive behaviors. The relationship in which professors are sensitive to feelings and self-conceptions of their learners, expression of constructive criticism in confidence and appreciation from learners, empathy for their difficulties, supportive and friendly behavior that makes enjoyable the learning environment can have an effective role in reducing the academic burnout. Some researchers showed that teachers who are sympathetic, supportive and sincere and conduct leadership without much rigor will cause to increase the cognitive and emotional situations and reduce the risk of academic burnout. Therefore, it is suggested that professors consider important their supportive role and its important effects in reducing stress and academic burnout.

\section{References}

Abtahi, S. Hasan; Torabian, Mohsen (2010). Reviewing the fulfilment of goals of higher education based on the document of country's twenty years perspective using Analytical Hierarchy Process (Ahp). Research in educational systems.

Eslami, Muhammad Ali (2011). The relationship of mental-physical health and spiritual intelligence with the academic burnout among undergraduate students of Allameh Tabatabai University in Tehran. Master's thesis, University of Allameh Tabatabai, Tehran.

Olson, Matthew, H.; Hergenhan, B. R. (2009). An introduction to learning theory. (Tr. by Ali Akbar Saif, 2012). Publication of Dowran.

Basharat, Mohammad Ali; Houminiyan, Davoud; Ghahramani, Hussein; Naghipour Givi, B. (2011). Mediating effect of sportive selfefficacy on the relationship between perfectionism and competitive anxiety. Development and kinesthetic learning, №. 8.

Biabangard, Ismail (2008). Research methods in Psychology and Educational Sciences. Publication of Dowran.

Pourseyed, S. Mehdi (2011). Direct and indirect relationship between perceived stress, perfectionism and social support with academic burnout among students of basic sciences level of medicine of Ahvaz' Jundishapur. Master's thesis, Shahid Chamran University.

Pouladi Reyshahri, R. (1995). Constructing and validating a scale of stress factors in students of Sh. Chamran University. Master's thesis, Sh. Chamran University.

Toutounchi, Maryam; Samani Siamak, Zandi Qashqai, Kerematoolah (2012). The role of mediation of self-conception for perfectionism and mental health in adolescents of the city of Shiraz in 1391. Magazine of University of Medical Sciences. FASA, second year, No. 3.

Khateri, Mona (2005). Reality Therapy impact on self-esteem and self-conception, focusing on choice theory. Master's thesis, Allameh Tabatabai University.

Dadvar, Samaneh (2014). The relationship of academic procrastination and academic burnout with educational achievement among higher education students. Master's thesis, University of Al-Zahra, Tehran.

Rostami, Z.; Abedi, Mohammad Reza; Shufly Wilmarby (2011). Normalization of Maslach's academic burnout scale in female students of Isfahan University. New educational approaches: Spring and Summer 2011, Vol. 6, №. 1.

Rio, Marshall (2005). Motivation and excitement. Tr. by Yahia S. Mohammad (2010). Tehran: Publication of Virayesh.

Santrak, John. W. (2003). Psychology. Translated Fyrvzbkht, M. (2006). Rasa cultural services.

Savyz, M. (2012). Investigating the relationship between perfectionism, academic burnout, quality of learning experiences and academic achievement among Higher Education students of Yazd University. Master's thesis, University of Yazd.

Saif, Ali Akbar (2009). New education psychology. Teheran: Agah.

Shah Bakhsh, A. (2011). Investigating and comparing the relationship of perfectionism, social support and academic burnout in students with high and low levels academic burnout of Allameh Tabatabai University, Master's thesis, University of Allameh Tabatabai.

Abargouei Azizi, M. (2010). The relationship of self-efficacy and quality of learning experiences with academic burnout of MA students of Allameh Tabatabai University in Tehran. Master's thesis, University of Allameh Tabatabai, Tehran.

Alizadeh, Yasser (2009). Relationship of attachment (to mother, father and peers) with perfectionism and academic performance of male students in public high schools in llam. Master's thesis of Educational psychology, University of Sh. Chamran.

Fouladchang, M., (2003). Evaluation of female students belief of self-efficacy of the province Fars and providing appropriate working procedures. Master's thesis. University of Allameh Tabatabai.

Fouladvand, Khadijah; Farzad, V.; Shahraray, M.; Sangari, A. (1009). The effect of social support, educational stress and self-efficacy on mantal-physical health. Contemporary Psychology, Volume IV, N. 2.

Keramati, H. (2001). Investigating the relationship between perceived self-efficacy of students of the junior high school level 3 of Tehran City and attitude toward math with their progress. Master's thesis, University of Tarbiat Moalem of Tehran.

Najjarian, Bahman; Attari, Yousof Ali; Zargar, Yadollah (2001). Constructing and validating a scale of perfectionism of Ahvaz. Magazine of educational sciences and psychology, vol. 3, No. 4.

Najafi, Mahmoud; Fouladchang, Mahboube (2007). Relationship between self-efficacy and mental health in school students. Scientificresearch two-monthly journal of University of Shahed. New vol., No. 22.

Naami, Abdul Zahra (2009). The relationship of the quality of learning experiences with academic burnout of students of MA of Sh. Chamran university of Ahvaz. Journal of psychological studies. Vol. 5, No. 3.

Hashemi Sheykh Shabani, S. Esmaeil; Bazrafkan, Hesam; Azizi, Mohsen (2013). Factor Structure of Maslach's academic burnout questionnaire in female students. Quarterly of social-psychological studies of women. 11 $11^{\text {th }}$ year, No. 1, spring of 2013.

Balogun, J. A, Helgemoe, S, Pellegrini, E \& Hoeberlein, T, (1996). Academic performance is not a viable determinant of physical therapy students' burnout, Perceptual and Motor Skills, 83, 21-22. 
Baron, R. M. and Kenny, D. A. (1986) "The Moderator-Mediator Variable Distinction in Social

Chang, E. C, Rand, K. L \& Strunk, D. P, (2000). Optimism and risk for burnout among working college students: Stress as a mediator, Personality and Individual Differences, 29, 255-263.

Cherniss, C. (1992). Long-term consequence of burnout: An exploratory study. Journal of Organizational, Behavior, 13, 1-11.

Cherniss, C. (1993). The role of professional self-efficacy in the etiology and amelioration of burnout. In W. B. Schanfeli, C. Maslach, \& T. Marek (Eds.), Professional burnout: Recent developments in theory and research (pp. 115-129). Washington, DC: Taylor \& Francis.

Cohen, In S. \& S. L. Syme (Eds.) (1985). Social Support and Health. San Francisco: Academic Press.

Cordes, C. L., \& Dougherty, T. W. (1993). A review and integration of resource on job burnout. Academy of Management Review, 18(4), 621-656.

danielsen, anne g. oddrun samdal. jørn hetland. bente wold(2009). School-Related Social Support and Students' Perceived Life Satisfaction. The Journal of Educational Research

Demerouti ,E , Bakker , A.B, Nachreiner, E \& Schaufeli, W.B , (2001). The job demands-resources model of burnout, Journal of Applied Psychology, 86, 499-512

Enns, M. W., \& Cox, B. (2002). The nature and assessment of perfectionism: A critical analysis. In G.L. Flett \& P. L. Hewitt (Eds.), Perfectionism: Theory, research, and treatment (pp. 33-62). Washington, DC: American Psychological Association.

Fimian, M. J, Fastenau, P. A, Tashner, J. H \& Cross, A. H, (1989). The measure of classroom stress and burnout among gifted and talented students, Psychology in the Schools, 26, 139-153.

Ganster, D. C., \& Victor, B. (1988). The impact of social support on mental physical health.

Gold, Y, Bachelor, P \& Michael, W. B, (1989). The dimensionality of a modified form of the Maslach Burnout Inventory for university students in a teacher- training program, Educational and Psychological Measurement, 49, 549-561.

Greenglass, E. R, Burke, R. J \& Fiksenbaum, L, (2001). Workload and Burnout in nurses, Journal of Community and Applied Social Behavior and Personality, 11, 211-215.

Hallsten, L., 1993. Burning out: a framework. In: Schaufel, W.B., Maslach, C., Marek, T. (Eds.), Professional Burnout Developments in Theory and Research. Taylor and Frances, Washington, DC, pp. 95-113.

Hobfoll, S.E., Freedy, J., 1993. Conservation of resource: a general stress theory applied to burnout. In: Schanfeli, W.B., Maslach, C., Marek, T. (Eds.), Professional Burnout: Recent Developments in Theory and Research. Taylor \& Francis, Washington, DC, pp. $115-129$.

Lacovides, A, Fountoulakis, K. N, Kaprinis, St \& Kaprinis, G, (2003). The relationship between job strees,burnout and clinical depression, Journal of Applied Disorders,75,209-221.

Lee,R \& Ashforth, B, (1996).A meta-analytic examination of the correlates of the three dimension of job burnout, Journal of Applied Psychology, 81,123-133

Malecki Christine Kerres. Demaray Michelle Kilpatrick, and Elliott Stephen N(2000). child and adolescent social support scale - casss

Martinez, I, Marques, A Salanova, M \& Lopez da Silva, A, (2002). Burnout en estudiantes universitarios de

Espana y Portugal [Burnout among university students in Spain and Portugal], Ansiedad y Estre's, 8, 13-23.

Maslach, C \& Jackson, S.E, (1984).Burnout in organizational setting, Applied Social Psychology Annual,5,133-153.

Maslach, C., Pines, A., 1977. The burn-out syndrome in the daycare setting. Child Care Quarterly 6 (2), 100-113.

Maslach, C, Schaufeli, W.B \& Leiter, M.P, (2001).Job burnut, Annual Review of psychology,52,397-422.

McCarthy, M. E, Pretty, G. M \& Catano, V, (1990). Psychological sense of community and student burnout, Journal of College Student Development, 31, 211-216.

Ross, R. R, Altmaier, E. M \& Russel, D. W, (1989). Job Stress, Social support, and burnout among counseling center staff, Journal of Counseling Psychology, 4, 464-670.

Russell, D.W., Altmaier, E., Velzen, D.V., 1987. Job-related stress, social support, and burnout among classroom teachers. Journal of Applied Psychology 72 (2), 269-274.

Salanova, M., PeirÃ $\tilde{A}^{3}$, J.M., \& Schaufeli, W.B. (2002). Self-efficacy specificity and burnout among information technology workers: An extension of the Job Demands-Control Model. European Journal of Work and Organizational Psychology, 11-25

Salmela- Aro, K \& Naatanen, P, (2005). PPI-10: Nuorten kouluuupumus-menetelma, Adolescenta school burnout method, Helsinki,Finland, Edita.

Sandoval, J, (1993). Personality and burnout among school Psychologists, Psychology in the schools, 30, 321-326.

Schutte, N., Toppinnen, S., Kalimo, R., \& Schaufeli, W. B. (2000). The factorial validity of the Maslach Burnout Inventory-General Survey across occupational groups and nations. Journal of Occupational and Organizational Psychology, 73, 53-66.

Sherer, M., Maddux, J. E., Mercandante, B., Prentice-Dunn, S., Jacobs, B., \& Rogers, R. W. (1982). The Self-Efficacy Scale: Construction and validation. Psychological

Reports, 51, 663-671.

Toppinen_Tanner,S,Ojaarvi,A,Vaananen,A,Kalimo,R\&Jappinen,P,(2005).Burnout as a predictor of medically certified sickleave absences and their diagnosed causes, Behavioral Medicine,31,18-27.

Sand, G \& Miyazaki, A. D, (2000). The impact of Social support on salesperson burnout components,Psychology and Marketing, 17, 1326.

Yang, Hui-jen. Factors affecting student burnout and academic achievement in multiple enrollment programs in taiwan' s technicalvocational colleges. International journal of educational development 24 (2004) 283-301. 
Yang, Hui-Jen\&Farn, cheng kiang (2005). An Investigation The Factors MIS Student Burnout In technical- vocational college. Camputersin human behavior

Zallars, K. L, Perrewe, P. L \& Hochwarter, W. A, (2000) burnout in health care: The role of five factors of personality, Journal of Applied Social Psychology, 30, 1570-1598.

Zhang,Yiwen; Gan,Yiqun\&Cham, Heining. Perfectionism, academic burnout and engagement among Chinese college students: A structural equation modeling analysis. Personality \& individual differenses 43 (2007) 1529-1540. 